\title{
A COMPARATIVE STUDY OF LIGNOCAINE, LIGNOCAINE WITH DEXMEDETOMIDINE AND LIGNOCAINE WITH KETAMINE FOR IVRA IN UPPER LIMB SURGERIES
}

\author{
Ravindra S. Giri' ${ }^{1}$ P. G. Raghavendra ${ }^{2}$
}

1 MBBS, MD, Department of Anaesthesia, Mahadevappa Rampure Medical College, Kalaburagi, Karnataka, India. 2MBBS, Department of Anaesthesia, Mahadevappa Rampure Medical College, Kalaburagi, Karnataka, India.

\begin{tabular}{l}
\hline ABSTRACT \\
DACKGROUND \\
hexmedetomidine and Ketamine have been shown to decrease anaesthetic requirements and to induce analgesia in patients. They \\
Aim- To evaluate the effects of dexmedetomidine and ketamine when added to lignocaine in IVRA.
\end{tabular}

\section{MATERIALS AND METHODS}

After Institutional approval and informed consent, 90 ASA 1 and 2 volunteers were taken into the study. In Group A, 30 patients were randomly allocated to receive IVRA for upper limb with $3 \mathrm{mg} / \mathrm{kg}$ of $0.5 \%$ lignocaine; in Group B, 30 patients randomly received IVRA of upper limb with $3 \mathrm{mg} / \mathrm{kg}$ of $0.5 \%$ lignocaine with $0.5 \mathrm{mcg} / \mathrm{kg}$ dexmedetomidine and Group C patients randomly received IVRA of upper limb with $3 \mathrm{mg} / \mathrm{kg}$ of $0.5 \%$ lignocaine with $0.5 \mathrm{mg} / \mathrm{kg}$ ketamine. The onset of sensory, complete motor block and tourniquet pain were assessed and any symptoms after cuff deflation were recorded. Usual haemodynamic monitoring was used.

Statistical Analysis- ANOVA (Analysis of Variance) and Chi-square tests were used for data analyses; p value of $<0.05$ was considered significant.

\section{RESULTS}

Groups A, B and C were comparable in demographic and surgical parameters. The speed of onset of sensory and motor block was higher in Group C (Ketamine) ( $p<0.0001$ ). The tourniquet pain occurred significantly later in Group B (Dexmedetomidine) $(\mathrm{p}<0.0001)$. There were few incidences of bradycardia in Group B.

\section{CONCLUSION}

In conclusion, the present study suggested that dexmedetomidine and ketamine will modify the action of local anaesthetic, providing a shorter onset time of sensory and motor block and longer duration of action in IVRA.

\section{KEY WORDS}

IVRA: Intravenous Regional Anaesthesia, Local Anaesthetic: Lignocaine Hydrochloride, $\alpha-2$ Agonist: Dexmedetomidine, Ketamine. HOW TO CITE THIS ARTICLE: Giri RS, Raghavendra PG. A comparative study of lignocaine, lignocaine with dexmedetomidine and lignocaine with ketamine for IVRA in upper limb surgeries. J. Evolution Med. Dent. Sci. 2018;7(33):3648-3652, DOI: $10.14260 /$ jemds/2018/819

\section{BACKGROUND}

Intravenous Regional Anaesthesia (IVRA) was introduced into clinical practice by August Bier in 1908, but was forgotten for nearly half a century until it was reintroduced by Holmes in Great Britain in 1963. Since then it became widely popular and numerous reports from all over the world have appeared testifying to its efficacy in properly selected cases. The factors to be considered while performing this technique are possible reaction to the agents used and the anticipated length of procedure. Since the analgesia is dependent upon the uninterrupted presence of the tourniquet, it provides satisfactory analgesia for most surgical procedures on distal parts of the limbs. ${ }^{1}$

This form of analgesia is ideally suited for emergencies, where patient is with full stomach or suffering from other

'Financial or Other Competing Interest': None.

Submission 07-07-2018, Peer Review 31-07-2018,

Acceptance 06-08-2018, Published 11-08-2018.

Corresponding Author:

Dr. P. G. Raghavendra,

MBBS, Department of Anaesthesia,

Mahadevappa Rampure Medical College,

Kalaburagi, Karnataka, India.

E-mail: drpgraghavendra@gmail.com

DOI: $10.14260 /$ jemds $/ 2018 / 819$ diseases that contraindicates general anaesthesia. Moreover the feasibility and simplicity of execution of this method, its effectiveness and its lack of any side effects have been gratifying. The equipment needed is minimal. IVRA is particularly suitable for day care surgeries, as it requires minimal preparation and premedication. ${ }^{2}$

IVRA is suitable for distal limb surgeries like ganglion excision, carpal tunnel release, decompression of de Quervain's disease, manipulative reduction and dislocations of bones of forearm, amputations, wound debridement, tendon repair, foreign body removal, open reductions of fracture of forearm bones etc.

In recent years, alpha- 2 adrenergic receptor agonists ${ }^{3}$ have been the focus of interest for their sedative, anxiolysis, analgesic and perioperative sympatholytic and cardiovascular stabilizing effects with reduced anaesthetic requirements.

Dexmedetomidine, ${ }^{4}$ a stereoisomer of medetomidine is a highly selective alpha-2 adrenergic agonist and has been shown to decrease anaesthetic requirements by upto $90 \%$ and to induce analgesia in rats, volunteers and patients. It has been used successfully in combination with local anaesthetics for procedures like spinal, ${ }^{5}$ epidural ${ }^{6}$ and brachial blocks ${ }^{7}$ 
where it has been found to enhance/ potentiate the action of local anaesthetics.

Ketamine, a phencyclidine derivative exerts noncompetitive blockade of NMDA receptors and also has local anaesthetic properties, which have been studied as a sole agent for IVRA. ${ }^{8}$ Adequate IVRA was produced by ketamine $0.3 \%$ and $0.5 \%$.

The present study was designed to evaluate the quality, onset of sensory, onset of motor blockade and onset of tourniquet pain in IVRA with $0.5 \mathrm{mcg} / \mathrm{kg}$ dexmedetomidine added to $3 \mathrm{mg} / \mathrm{kg}$ of $0.5 \%$ lignocaine and $0.5 \mathrm{mg} / \mathrm{kg}$ ketamine added to $3 \mathrm{mg} / \mathrm{kg}$ of $0.5 \%$ lignocaine.

\section{MATERIALS AND METHODS}

This prospective, randomised, double-blinded study was conducted after obtaining clearance from Institutional Ethical Committee of the Institute and written informed consent from all patients.

The study comprised of 90 patients belonging to either sex and age between 18 and 60 years. The sample size was taken for convenience. All the patients belonged to ASA (American Society of Anesthesiologists) grade 1 or 2. Patients were randomly divided into three groups:

\section{Randomisation of the population is allocated into these} defined groups according to computer generated random numbers-

Group A- received IVRA for upper limb with $3 \mathrm{mg} / \mathrm{kg}$ of $0.5 \%$ lignocaine.

Group B- received IVRA of upper limb with $3 \mathrm{mg} / \mathrm{kg}$ of $0.5 \%$ lignocaine with $0.5 \mathrm{mcg} / \mathrm{kg}$ dexmedetomidine.

Group C- received IVRA of upper limb with $3 \mathrm{mg} / \mathrm{kg}$ of $0.5 \%$ lignocaine with $0.5 \mathrm{mg} / \mathrm{kg}$ ketamine.

Detailed history was taken, and complete clinical examination was done to exclude patients with history of epilepsy, hypersensitivity to local anaesthetics, neurological, cardiac, haemolytic diseases, Raynaud's disease and sickle cell anaemia. Routine investigations like blood grouping, haemoglobin, blood urea and blood sugar were done. ECG whenever indicated was undertaken to rule out the presence of any cardiac disease. Pre-operative temperature, pulse rate, respiratory rate, blood pressure and condition of heart and lungs are noted. Patient's weight was recorded. Patients were explained about the procedure of intravenous regional anaesthesia.

The necessary equipment and drugs were kept ready before proceeding with the technique. Standard monitors like pulse oximetry, NIBP and ECG were connected.

An 18-G intravenous cannula was inserted into a vein of the non-operative limb for the purpose of administering fluids or drugs. Another 22-G cannula was inserted into the suitable vein on dorsum of hand that was to be operated as distally as possible and firmly secured.

\section{Tourniquet}

Cotton padding was placed on the proximal part of the limb to be operated. Double tourniquets were set up and connected to pneumatic pressure gauge.

\section{Exsanguinating the Extremity}

The arm to be operated is elevated to 90-degree angle from the body above the level of heart for 5 minutes to drain the blood from the limb. Esmarch bandage was wrapped tightly around the arm from the most distal part to near the pneumatic tourniquet to further exsanguinate. The proximal cuff was inflated to $100 \mathrm{mmHg}$ higher than the systolic blood pressure of patient. The absence of radial artery pulsations and failure of pulse oximetry tracing in ipsilateral index finger was confirmed.

\section{Injecting the Anaesthetic Solution}

The limb was placed horizontally, and local anaesthetic was injected steadily.

Group A- Patients received solution containing $0.5 \%$ lignocaine $3 \mathrm{mg} / \mathrm{kg}$.

Group B- Patients received solution containing 0.5\% lignocaine $3 \mathrm{mg} / \mathrm{kg}$ and dexmedetomidine $0.5 \mathrm{mcg} / \mathrm{kg}$.

Group C- Patients received solution containing $0.5 \%$ lignocaine $3 \mathrm{mg} / \mathrm{kg}$ and ketamine $0.5 \mathrm{mg} / \mathrm{kg}$.

After injection IV cannula was removed and pressure was applied to venepuncture site for some time till bleeding stops.

\section{Assessment of Block}

Six areas supplied by radial, median and ulnar nerves were tested in sequence with the patient unable to observe testing. At 90-second interval after administration, the sensory block was assessed by using a cube of ice placed in sterile test tubes. Motor function was assessed by asking the patient to flex and extend his wrist and fingers.

Complete motor block was considered when no voluntary movement was possible.

\section{Tourniquet Pain}

Proximal tourniquet deflated after inflating distal tourniquet once patient complains of discomfort. Then distal cuff was inflated to $250 \mathrm{mmHg}$ and proximal cuff was deflated.

\section{Tourniquet Release}

At the end of case/ after 45 mins, the tourniquet was deflated using deflation and inflation technique before the cuff was let down permanently.

\section{Monitoring after Tourniquet Release}

The patients were monitored for any change in pulse rate, blood pressure, loss of consciousness and for any signs of systemic toxicity like twitching, convulsions and ECG abnormalities. Sensory assessment was continued until full recovery occurred at all six sites.

\section{Statistical Analysis}

One-Way ANOVA (Analysis of Variance) was used for the comparison between the groups and Chi-square test was applied for age, sex and ASA grades. $\mathrm{P}$ value of $<0.05$ was considered significant. 
RESULTS

\begin{tabular}{|c|c|c|c|}
\hline & Group A & Group B & Group C \\
\hline Mean & 38.6 & 40.3 & 33.2 \\
\hline S.D & 15.3 & 14.5 & 9.6 \\
\hline \multicolumn{4}{|c|}{ Table 1. Age Distribution } \\
\hline
\end{tabular}

P value $<0.05$

The present study demonstrated that patients were between the age of 18 - 60 years with mean age of 38.6 in Group A, 40.3 in Group B and 33.2 in Group C.

\begin{tabular}{|c|c|c|c|}
\hline & Group A & Group B & Group C \\
\hline Male & 17 & 16 & 13 \\
\hline Female & 13 & 14 & 17 \\
\hline \multicolumn{3}{|c|}{ Table 2. Sex Distribution } \\
\hline
\end{tabular}

$\mathrm{p}$ value $<0.05$

In our study there were 17 male patients and 13 female patients in Group A, 16 male patients and 14 female patients in Group B and 13 male patients and 17 female patients in Group C.

\begin{tabular}{|c|c|c|c|}
\hline & Group A & Group B & Group C \\
\hline Mean & 6.6 & 4.3 & 2.4 \\
\hline S.D & 1.4 & 0.9 & 0.7 \\
\hline
\end{tabular}

Table 3. Statistical Analysis of onset of Sensory Blockade

$\mathrm{p}$ value $<0.05$

The present study demonstrated that sensory blockade occurred at a mean time of 6.6 mins in Group A, 4.3 mins in Group B and 2.4 mins in Group C.

\begin{tabular}{|c|c|c|c|}
\hline & Group A & Group B & Group C \\
\hline Mean & 16.6 & 13.9 & 7.8 \\
\hline S.D & 2.1 & 1.9 & 1.4 \\
\hline \multicolumn{2}{|l|}{ Table 4. Statistical Analysis of onset of Motor Block } \\
\hline
\end{tabular}

$\mathrm{p}$ value $<0.05$

The present study demonstrated that onset of motor block occurred at a mean time of 16.6 mins, 13.9 mins and 7.8 mins with standard deviation of $2.1,1.9$ and 1.4 mins in Group A, Group B and Group C respectively.

\begin{tabular}{|c|c|c|c|}
\hline & Group A & Group B & Group C \\
\hline Mean & 11.3 & 16.9 & 13.2 \\
\hline S.D. & 3.5 & 2.8 & 2.1 \\
\hline \multicolumn{4}{|c|}{ Table 5. Statistical Analysis of onset of Tourniquet Pain } \\
\hline
\end{tabular}

$\mathrm{p}$ value $<0.05$

The present study demonstrated that onset of tourniquet pain occurred at a mean time of 11.3 mins, 16.9 mins and 13.2 mins with standard deviation of 3.5, 2.8 and 2.1 mins in Group A, Group B and Group C respectively.

\begin{tabular}{|c|c|c|c|}
\hline & Group A & Group B & Group C \\
\hline Mean & 49 & 48 & 45 \\
\hline S.D & 19.5 & 16.8 & 11.6 \\
\hline \multicolumn{2}{|c|}{ Table 6. Statistical Analysis of duration of Surgery } \\
\hline
\end{tabular}

p value of 0.05
The present study demonstrated that duration of surgery took a mean time of 49 mins, 48 mins and 45 mins with standard deviation of 19.5, 16.8 and 11.6 mins in Group A, Group B and Group C respectively.

\begin{tabular}{|c|c|c|c|}
\hline & Group A & Group B & Group C \\
\hline Age (years) & $38.6+/-15.3$ & $40.3+/-14.5$ & $33.2+/-9.6$ \\
\hline $\begin{array}{c}\text { Sex (Male) } \\
\text { (Female) }\end{array}$ & 17 & 16 & 13 \\
\hline $\begin{array}{c}\text { Onset of Sensory } \\
\text { Block (minutes) }\end{array}$ & $6.6+/-1.4$ & $4.3+/-0.9$ & $2.4+/-0.7$ \\
\hline $\begin{array}{c}\text { Onset of motor } \\
\text { Block (Minutes) }\end{array}$ & $16.6+/-2.1$ & $13.9+/-1.9$ & $7.8+/-1.4$ \\
\hline $\begin{array}{c}\text { Onset of } \\
\text { Tourniquet Pain } \\
\text { (Minutes) }\end{array}$ & $11.3+/-3.5$ & $16.9+/-2.8$ & $13.2+/-2.1$ \\
\hline $\begin{array}{c}\text { Duration of } \\
\text { Surgery } \\
\text { (Minutes) }\end{array}$ & $49+/-19.5$ & $48+/-16.8$ & $45+/-11.6$ \\
\hline \multicolumn{3}{|c|}{ Table 7 } \\
\hline
\end{tabular}

$\mathrm{p}$ value $<0.05$

Total 90 patients were divided into 3 groups of 30 each. Age, sex and duration of surgery were comparable in between groups ( $p>0.05)$. The onset of sensory and motor block was faster in Group C as compared to Group B ( $p<0.0001$ ), whereas duration of onset of tourniquet pain was longer in Group B than Group C ( $<<0.0001)$.

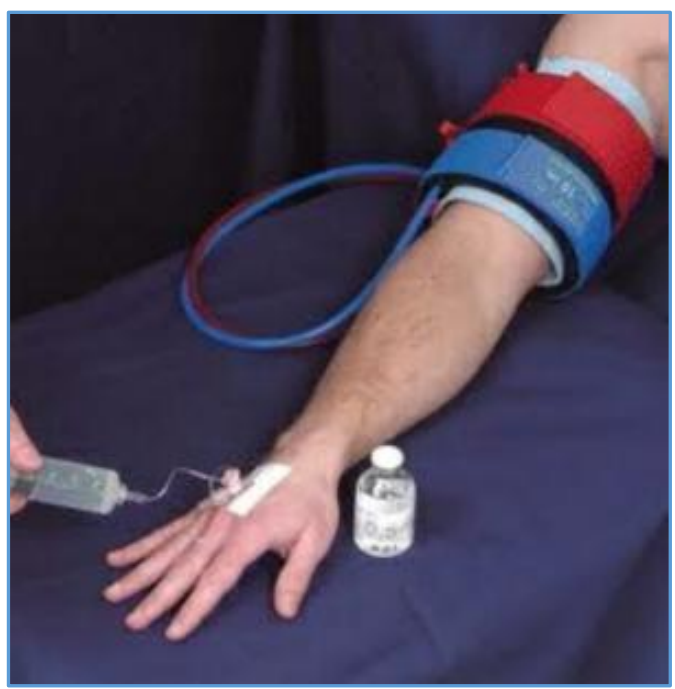

\section{DISCUSSION}

Intravenous regional anaesthesia is a simple, cost effective and safe technique for surgery. It is a proven, time tested technique for surgeries of upper/ lower limb. It produces rapid onset of analgesia in 5-10 minutes with good muscle relaxation. IVRA is particularly suitable for day care surgeries, as it requires minimal preparation and premedication. ${ }^{1}$

Disadvantage of IVRA is tourniquet pain, as tourniquet has to be kept inflated continuously throughout the procedure and limited duration of surgery can be allowed.

In order to improve quality of block, duration of analgesia and sedation, several trials have been conducted with dexmedetomidine and ketamine.

Memis et $\mathrm{al}^{4}$ in the year 2004 achieved IVRA using $0.5 \%$ lignocaine $3 \mathrm{mg} / \mathrm{kg}$ with saline in control group and $0.5 \%$ 
lignocaine $3 \mathrm{mg} / \mathrm{kg}$ with $0.5 \mathrm{mcg} / \mathrm{kg}$ dexmedetomidine in study group.

Based on this, we used $0.5 \mathrm{mcg} / \mathrm{kg}$ dexmedetomidine with lignocaine in the present study.

The present study was conducted on 90 patients undergoing various upper limb procedures. The patients were randomly allotted to three groups:- Group A, Group B and Group C. Group A patients underwent IVRA with 0.5\% lignocaine alone. Group B patients underwent IVRA with combination of dexmedetomidine $0.5 \mathrm{mcg} / \mathrm{kg}$ and $0.5 \%$ lignocaine. Group C patients underwent IVRA with $0.5 \mathrm{mg} / \mathrm{kg}$ ketamine and $0.5 \%$ lignocaine.

90 patients were randomly assigned for upper limb surgeries for short procedure after adequate starvation, physical status and basic investigations.

The present study demonstrated that patients were between the age 18 - 60 years with mean age of 38.6 in Group A, 40.3 in Group B and 33.2 in Group C.

In our study there were 17 male patients and 13 female patients in Group A, 16 male patients and 14 female patients in Group B and 13 male patients and 17 female patients in Group C.

\section{Exsanguination}

John Mabee et $\mathrm{al}^{2}$ showed that while Esmarch was the most effective exsanguination method, arm elevation or arterial compression also were effective.

Hence, in our study first gravitational drainage was done followed by Esmarch bandage application.

\section{Dose Selection}

In our study Group A received $0.5 \%$ lignocaine $3 \mathrm{mg} / \mathrm{kg}$, Group B received $0.5 \%$ lignocaine $3 \mathrm{mg} / \mathrm{kg}$ with dexmedetomidine $0.5 \mathrm{mcg} / \mathrm{kg}$ and Group C received $0.5 \%$ lignocaine $3 \mathrm{mg} / \mathrm{kg}$ with ketamine $0.5 \mathrm{mg} / \mathrm{kg}$.

Similarly, Dilek Memis et $\mathrm{al}^{4}$ used $0.5 \%$ lignocaine $3 \mathrm{mg} / \mathrm{kg}$ diluted to $40 \mathrm{~mL}$ in lignocaine group and $0.5 \%$ lignocaine $3 \mathrm{mg} / \mathrm{kg}$ with dexmedetomidine $0.5 \mathrm{mcg} / \mathrm{kg}$ diluted to $40 \mathrm{~mL}$ in dexmedetomidine group.

Abhishek Gupta et $\mathrm{al}^{3}$ used $40 \mathrm{~mL}$ 0.5\% lignocaine and either dexmedetomidine $0.5 \mathrm{mcg} / \mathrm{kg}$ in Group $\mathrm{A}$ or dexmedetomidine $1 \mathrm{mcg} / \mathrm{kg}$ in Group B.

Esmaoglu et al $^{9}$ used $3 \mathrm{mg} / \mathrm{kg}$ lignocaine diluted with saline in control group and $1 \mathrm{mcg} / \mathrm{kg}$ of dexmedetomidine $+3 \mathrm{mg} / \mathrm{kg}$ lignocaine in dexmedetomidine group.

Durrani et $\mathrm{al}^{10}$ found that use of ketamine $0.3 \%$ for regional anaesthesia of upper extremity was adequate for complete sympathetic, sensory and motor blockade.

Kaul et al 11 compared ketamine $0.5 \% 3 \mathrm{mg} / \mathrm{kg}$ with lignocaine $0.5 \% 3 \mathrm{mg} / \mathrm{kg}$.

The present study showed significant reduction of onset of sensory and motor block in Group B and Group C. Sensory and motor block recovery times were also statistically prolonged in these groups $(\mathrm{p}<0.001)$.

In a study conducted by Dilek Memis et $\mathrm{al}^{4}$ also found significant reduction in onset times of sensory and motor block in Group LD as compared to Group L. Sensory and motor block recovery times were also statistically prolonged in this group.

\section{Toxicity Reaction}

The complications of IVRA usually are caused by the systemic toxicity of the agent used. Brown and co-workers in their 20 years' experience described IVRA without mortality and morbidity. In one series of 1400 patients, only 8 patients had CNS stimulation and only three had frank convulsions. ${ }^{12}$

Dunbar and Mazze found no arrhythmias and only a slight drop in blood pressure or slight bradycardia on release of the tourniquet. ${ }^{13}$

Kennedy and co-workers in their patients found a $15 \%$ incidence of ECG changes and recorded one cardiac arrest that was preceded by bradycardia. ${ }^{14}$

They felt that smaller the dose and greater the injection release interval, the chances of toxic reactions were rare. In our study, there were no significant changes in heart rate or ECG.

\section{Blood Levels}

Mazze and co-workers reported a blood level of $1.5 \mathrm{mcg} / \mathrm{mL}$ following $3 \mathrm{mg} / \mathrm{kg}$ of $0.5 \%$ lignocaine. ${ }^{15}$

Hargrove and co-workers found that maximum levels of local anaesthetic in venous blood from other arm did not exceed $2 \mathrm{mcg} / \mathrm{mL} .{ }^{16}$

In our study, we could not estimate blood levels due to lack of facilities.

\section{Complications Related to the use of Tourniquet}

A study reviewed an estimated 6,30,000 tourniquet application found an incidence of peripheral nerve damage of 1 in 80,000. The incidence was higher in procedures involving the upper limb than in those involving lower limb. The tourniquet time varied from 20 minutes to $2-1 / 2$ hours. ${ }^{17}$

Dilek Memis et $\mathrm{al}^{4}$ found that addition of dexmedetomidine found significant reduction in tourniquet and post-operative pain during IVRA.

In our study there were no complications related to the use of tourniquet and also it was found that addition of dexmedetomidine and ketamine reduce tourniquet pain during IVRA.

Ketamine, a phencyclidine derivative, an IV anaesthetic agent exerts a non-competitive blockade on N-methylaspartate (NMDA) receptors. Ketamine also has local anaesthetic qualities, which have been studied as a sole agent for IVRA. ${ }^{8}$ In addition to spinal cord, NMDA receptors have also been identified on peripheral unmyelinated sensory axons. This can explain why ketamine as an NMDA receptor antagonist was able to attenuate the tourniquet pain. Ketamine 0.5 and $0.3 \%$ produced adequate IVRA. Unpleasant psychotomimetic effects after the release of the tourniquet limit the usefulness of this use of ketamine. ${ }^{18}$ The onset of analgesia and motor blockade remains similar and all patients suffered from disorientation and hallucinations. There was an early onset of sensory and motor block and good postoperative analgesia, although postoperative analgesia was longer in the dexmedetomidine group. Ketamine has well known haemodynamic effects (Hypertension and tachycardia), but it failed to show any of these effects when given as an adjuvant in IVRA in our study. This could be due to the fact that the tourniquet was not deflated before 30 mins.

In recent years, alpha- 2 adrenergic receptor agonists ${ }^{4}$ have been the focus of interest for their sedative, anxiolysis, 
analgesic and perioperative sympatholytic and cardiovascular stabilising effects with reduced anaesthetic requirements. Dexmedetomidine, centrally acting $\alpha 2$ adrenergic agonist exerts powerful analgesic action. It enhances the local anaesthetic action of lignocaine via $\alpha 2 \mathrm{~A}$ adrenoceptor. Dexmedetomidine, ${ }^{4}$ a stereoisomer of medetomidine is a highly selective alpha 2 adrenergic agonist and has been shown to decrease anaesthetic requirements by upto $90 \%$ and to induce analgesia in rats, volunteers and patients. It has been used successfully in combination with local anaesthetics for procedures like spinal, ${ }^{5}$ epidural ${ }^{6}$ and brachial blocks, ${ }^{7}$ where it has been found to enhance/potentiate the action of local anaesthetics.

Perioperative dexmedetomidine administration decreases the requirements for opioid or non-opioid analgesics, both intra- and post-operatively.19 IV dexmedetomidine can be used as a premedication as it reduces patient's anxiety, sympathoadrenal responses and opioid analgesic requirements, but it did not reduce tourniquet pain. ${ }^{20,21}$ Dexmedetomidine produces hypertension and bradycardia until the central sympatholytic effect dominates, resulting in moderate decrease in both mean arterial pressure and heart rate from baseline. ${ }^{22}$

In our study, ketamine produced early onset of block and delayed onset of tourniquet pain, whereas dexmedetomidine when added in IVRA provided better postoperative analgesia.

\section{CONCLUSION}

The present study suggested that dexmedetomidine and ketamine will modify the action of local anaesthetic, providing a shorter onset time of sensory and motor block and longer duration of action in IVRA.

\section{REFERENCES}

[1] Miller DR. Anaesthesia. Vol. 2. 7th edn. Philadelphia: Churchill Livingstone 2005.

[2] Mabee J, Orlinsky M. Bier block exsanguination: a volumetric comparison and venous pressure study. Academic Emergency Medicine 2000;7(2):105-13.

[3] Abhishek G, Mamta M, Neeraj N, et al. Comparative study of two different doses of dexmedetomidine as adjunct to lignocaine in intravenous regional anaesthesia of upper limb surgeries. Int J of Sci Stud 2014;2(3):53-62.

[4] Memis D, Turan A, Karamanlioglu B, et al. Adding dexmedetomidine to lignocaine for intravenous regional anaesthesia Anesth Analg 2004;98(3):835-40.

[5] Swami SS, Keniya VM, Ladi SD, et al. Comparison of dexmedetomidine and clonidine (2 agonist drugs) as an adjuvant to local anaesthesia in supraclavicular brachial plexus block: a randomised double blind prospective study. Indian J Anaesth 2012;56(3):243-9.
[6] Gupta R, Bogra J, Verma R, et al. Dexmedetomidine as an intrathecal adjuvant for postoperative analgesia. Indian J Anaesth 2011;55(4):347-51.

[7] Bajwa SJ, Bajwa SK, Kaur J, et al. Dexmedetomidine and clonidine in epidural anaesthesia: a comparative evaluation. Indian J Anaesth 2011;55(2):116-21.

[8] Elmetwaly KF, Hegazy NA, Aboelseoud AA, et al. Does the use of ketamine or nitroglycerin as an adjuvant to lignocaine improve the quality of intravenous regional anesthesia? Saudi J Anaesth 2010;4(2):55-62.

[9] Esmaoglu A, Mizrak A, Akin A, et al. Addition of dexmedetomidine to lignocaine for intravenous regional anaesthesia. Eur J Anaesthesiol 2005;22(6):447-51.

[10] Durrani Z, Winnie AP, Zsigmond EK, et al. Ketamine for intravenous regional anesthesia. Anesth Analg 1989;68(3):328-32.

[11] Kaul TK, Mittal BR, Gupta S. Comparison of lignocaine and ketamine as intravenous regional anaesthetics. Indian J Anaesth 1993;41:234-9.

[12] Brown EM, Mcgriff JT, Maliinowski RW. Intravenous regional anaesthesia (Bier block): review of 20 years' experience. Can J Anaesth 1989;36(3 Pt 1):307-10.

[13] Dunbar RW, Mazze RI. Intravenous regional anaesthesia: experience with 779 cases. Anesth Analg 1967;46:806-13.

[14] Kennedy BR, Dutthie AM, Parbrook GD, et al. Intravenous regional anaesthesia: an appraisal. $\mathrm{Br}$ Med J 1965;1(5440):954-7.

[15] Mazze RL, Dunbar RW. Plasma lidocaine concentrations after caudal, lumbar epidural, axillary block and intravenous regional anaesthesia. Anaesthesiology 1966;27(5):574-9.

[16] Hargrove RL, Hoyle JR, Parker JB, et al. Blood lignocaine level following intravenous regional analgesia. Anaesthesiology 1966;21(1):37-41.

[17] Middleton RW, Varian JP. Tourniquet paralysis Aust N Z J Surg 1974;44(2):124-8.

[18] Roy DD, Deshpande RA. IVRA with ketamine: a study of 30 cases. Indian J Anesth 1987;35:355-8.

[19] Mizrak A, Gul R, Erkutlu I, et al. Premedication with dexmedetomidine alone or together with $0.5 \%$ lidocaine for IVRA. J Surg Res 2010;164(2):242-7.

[20] Scheinin H, Jaakola ML, Sjövall S, et al. Intramuscular dexmedetomidine as premedication for general anesthesia. Anesthesiology 1993;78(6):1065-75.

[21] Jaakola ML. Dexmedetomidine premedication before intravenous regional anesthesia in minor outpatient hand surgery. J Clin Anesth 1994;6(3):204-11.

[22] Dyck JB, Shafer SL. Dexmedetomidine pharmacokinetics and pharmacodynamics. Anesth Pharmacol Rev 1993;1:238-45. 